ARTIKEL PENELITIAN

\title{
HUBUNGAN NILAI FRAKSI EJEKSI VENTRIKEL KIRI DENGAN TINGKAT GEJALA ANSIETAS YANG DIUKUR MENGGUNAKAN BECK ANXIETY INVENTORY (BAI) PADA PASIEN GAGAL JANTUNG
}

\author{
Adinda Nadira Larasati ${ }^{1}$, Faisal Habib ${ }^{2}$ \\ ${ }^{1}$ Fakultas Kedokteran, Universitas Muhammadiyah Sumatera Utara \\ ${ }^{2}$ Bagian Ilmu Penyakit Dalam dan Kardiologi Fakultas Kedokteran, Universitas Muhammadiyah Sumatera \\ Utara \\ email: ${ }^{1}$ adinnala@gmail.com, ${ }^{2}$ faisalhabib@umsu.ac.id
}

\begin{abstract}
Heart failure is a progressive health problem with high mortality and morbidity in developed and developing countries including Indonesia. Heart failure can lead to chronic physical disability, which is a high economic burden. Chronic diseases, especially diseases that greatly affect functional abilities such as heart failure are associated with physical, psychological, and lifestyle changes that often cause difficulties in improving mental health. The prevalence of anxiety is much greater among people with chronic diseases. The level of anxiety experienced by individuals is influenced by psychological factors, social factors, the severity of medical conditions, and the presence of comorbid diseases. This study aims to determine the relationship between the value of left ventricular ejection fraction with the level of anxiety symptoms. This was descriptive analytic research with cross sectional design. The subjects in this study were heart failure patients at RSU Mitra Medika Amplas and RSU Putri Hijau Tk.II Kesdam I/BB Medan in November 2018 January 2019 (40 patients). This research used convenience sampling techniques and data analysis using the Kruskal-Wallis test. Retrieving data through filling out questionnaires (Beck Anxiety Inventory questionnaires) and medical records. The results showed that patients who had the most anxiety were 19 respondents (47,5\%), followed by patients with mild anxiety symptoms as many as 17 respondents (42.5\%), then heart failure patients with symptoms of severe anxiety were 4 respondents (10\%). Heart failure patients were found to have preserved (normal) ejection fraction 25 respondents (62,5\%) and mid-range ejection fraction (moderate) 11 respondents (27,5\%), reduced ejection fraction (decreased) 4 respondents (10\%). The results of the Kruskal-Wallis test obtained P value is 0.011 . The lower the value of the left ejection fraction, the more severe the level of anxiety symptoms felt by the patient.
\end{abstract}

Keywords: Heart failure, Ejection Fraction, Anxiety 


\section{PENDAHULUAN}

Gagal jantung merupakan masalah kesehatan yang progresif dengan angka mortalitas dan morbiditas yang tinggi di negara maju maupun negara berkembang termasuk Indonesia. ${ }^{1}$ Gagal jantung dapat mengakibatkan ketidakmampuan fisik secara kronik sehingga menjadi beban ekonomi yang tinggi. ${ }^{2}$

Menurut World Health Organization (WHO) pada tahun 2016, menyebutkan bahwa 17,5 juta orang di dunia meninggal karena penyakit kardiovaskuler pada tahun 2008, yang mewakili dari $31 \%$ kematian di dunia. Di Amerika Serikat penyakit gagal jantung hampir terjadi 550.000 kasus pertahun, dan di negaranegara berkembang kasus sejumlah 400.000 sampai 700.000 pertahun. $^{3}$

Penyakit kronis, terutama penyakit yang sangat mempengaruhi kemampuan fungsional seperti gagal jantung dikaitkan dengan adanya perubahan fisik, psikologis, dan gaya hidup sehingga sering menyebabkan kesulitan peningkatan kesehatan mental. ${ }^{4-7}$

Prevalensi ansietas jauh lebih besar di antara orang dengan penyakit kronis daripada populasi perawatan primer umum, dengan prevalensi mulai dari $30 \%$ hingga $50 \%$ pada orang dengan gagal jantung. ${ }^{8}$

Tingkatan ansietas yang dialami individu dipengaruhi oleh faktor psikologis, faktor sosial, beratnya kondisi medis, serta adanya penyakit komorbid. ${ }^{9}$ Ekspektasi terhadap adanya hal yang membahayakan pasien dapat memicu respon ansietas. Pasien yang baru saja terdiagnosa penyakit atau kecelakaan yang menyebabkan disabilitas melaporkan tingkat ansietas yang lebih tinggi daripada pasien yang sehat. ${ }^{10}$

\section{METODE PENELITIAN}

Jenis penelitian yang dilakukan bersifat deskriptif analitik dengan desain crosssectional yang bertujuan untuk menganalisis hubungan nilai fraksi ejeksi ventrikel kiri dengan tingkat gejala ansietas yang diukur menggunakan Beck Anxiety Inventory (BAI) pada pasien gagal jantung. Penelitian ini dilakukan di RSU Mitra Medika Amplas dan RSU Putri Hijau Tk.II Kesdam I/BB Medan. Metode penarikan sampel pada penelitian ini yaitu convenience sampling. Sampel penelitian ini adalah pasien gagal jantung yang berada di RSU Mitra Medika Amplas dan RSU Putri Hijau Tk.II Kesdam I/BB Medan berjumlah 40 orang dengan kriteria sebagai berikut:

Kriteria Inklusi :

1. Pasien dengan diagnosa gagal jantung

2. Pasien dengan hasil ekokardiografi

3. Pasien usia 16-80 tahun

4. Bersedia mengikuti penelitian

Kriteria Eksklusi :

1. Pasien yang telah terdiagnosis atau mempunyai riwayat gangguan ansietas

2. Sedang mengkonsumsi obat-obatan ansiolitik

3. Pasien dengan NYHA IV

4. Pasien dengan riwayat hipertiroid, dan gagal ginjal end stage

5. Pasien dengan disabilitas yang bermakna

Data yang dikumpulkan penelitian ini adalah data primer dan data sekunder. Data primer adalah data yang diperoleh langsung melalui kuesioner oleh peneliti yang dilakukan secara langsung terhadap sampel penelitian. Kuesioner tersebut terdiri dari lembar penjelasan, informed consent, status pasien gagal jantung, dan BAI. Dan data sekunder adalah data rekam medis yang digunakan untuk melihat hasil ekokardiografi pasien.

Data yang digunakan dalam penelitian ini didapat dengan menggunakan kuesioner dan rekam medis pasien.

Penelitian ini dilakukan dari bulan Desember 2018 sampai Februari 2019. Dengan menjumpai pasien gagal jantung yang datang ke poli jantung rumah sakit untuk memeriksa kondisi kesehatannya. Data status pasien dan kuesioner BAI diberikan secara langsung dan 
dijelaskan oleh peneliti. Pengambilan data penelitian dilakukan dengan memperhatikan kriteria inklusi dan eksklusi, sehingga pada penelitian ini didapatkan jumlah sampel sebanyak 40 pasien.

\section{HASIL DAN PEMBAHASAN}

Tabel 1 Distribusi Frekuensi Responden Berdasarkan Usia

\begin{tabular}{lll}
\hline Usia & $\mathbf{n}$ & $\mathbf{\%}$ \\
\hline$\leq 45$ tahun & 7 & $17,5 \%$ \\
$46-60$ tahun & 14 & $35,0 \%$ \\
$\geq 61$ tahun & 19 & $47,5 \%$ \\
\hline
\end{tabular}

Berdasarkan tabel 1 dapat diketahui bahwa kategori usia diatas 61 tahun adalah yang paling banyak dengan jumlah 19 responden $(47,5 \%)$, diikuti oleh kategori usia 46-60 tahun yang berjumlah 14 responden $(35,0 \%)$ dan kategori usia dibawah 45 tahun yaitu berjumlah 7 responden $(17,5 \%)$.

Tabel 2 Distribusi Frekuensi Responden Berdasarkan Jenis Kelamin

\begin{tabular}{lll}
\hline Jenis Kelamin & $\mathbf{n}$ & $\mathbf{\%}$ \\
\hline Pria & 17 & $42,5 \%$ \\
Wanita & 23 & $57,5 \%$ \\
Total & $\mathbf{4 0}$ & $\mathbf{1 0 0 \%}$ \\
\hline
\end{tabular}

Tabel 2 menunjukkan bahwa responden dengan jenis kelamin wanita lebih banyak dengan jumlah 23 responden $(57,5 \%)$ dan jumlah pria 17 responden $(42,5 \%)$ serta terdapat perbedaan yang sedikit antara jumlah wanita dan jumlah pria.

Berdasarkan tabel 3 diketahui responden dengan pendidikan terakhir yang paling banyak adalah SMA yaitu berjumlah 24 responden (60\%) dari total 40 pasien, kemudian diikuti dengan pendidikan terakhir SD, SMP dan S1 masing-masing berjumlah 5 responden $(12,5 \%)$ paling sedikit adalah responden dengan pendidikan terakhir S2 yaitu berjumlah 1 responden saja $(2,5 \%)$.

Tabel 3 Distribusi Frekuensi Faktor Perancu Berdasarkan Faktor-faktor Perancu

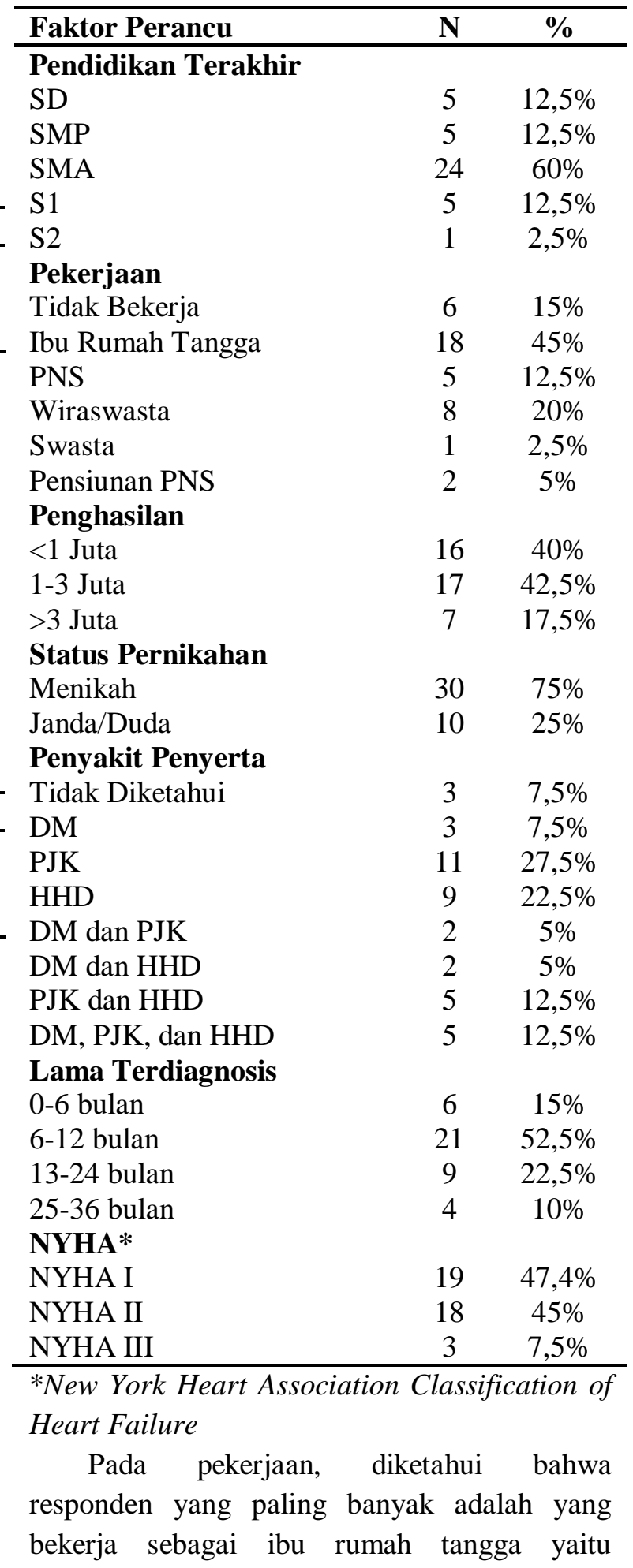


sebanyak 18 responden (45\%) dari total 40 responden, dan yang paling sedikit adalah bekerja di perusahaan swasta sebanyak 1 responden $(2,5 \%)$. Sementara pekerjaan lain seperti PNS adalah sebanyak 5 responden (12,5\%), wiraswasta sebanyak 8 responden (20\%), dan sebagai pensiunan PNS sebanyak 2 responden $(5 \%)$

Pada penghasilan dapat diketahui bahwa responden yang memiliki penghasilan per bulan 1-3 Juta sebanyak 17 responden (42,5\%), dan responden dengan penghasilan dibawah 1 Juta sebanyak 16 responden (40\%) serta ada 7 responden $(17,5 \%)$ dengan penghasilan diatas 3 Juta.

Status pernikahan yang paling banyak adalah status yang sudah menikah, yaitu sebanyak 30 orang dari jumlah total 40 responden, yaitu mencapai $75 \%$. Sementara pasien dengan status janda/duda sebanyak 10 responden $(25 \%)$.

Penyakit penyerta yang terbanyak adalah PJK yaitu sebanyak 11 responden dengan $27,5 \%$ dari jumlah total 40 responden, diikuti dengan HHD sebanyak 9 responden $(22,5 \%)$ dan PJK dan HHD sebanyak 5 responden $(12,5 \%)$. Sementara pada DM, PJK dan HHD didapati 5 responden $(12,5 \%)$, diikuti dengan DM sebanyak 3 responden (7,5\%), lalu DM dan PJK sebanyak 2 responden (5\%), DM dan HHD sebanyak 2 responden (5\%) serta responden tanpa penyakit penyerta atau tidak dikethui adalah sebanyak 3 responden $(7,5 \%)$.

Menurut lama diagnosisnya, dari tabel di atas diketahui bahwa lama diagnosis dari 6-12 bulan adalah yang terbanyak yaitu berjumlah 21 responden $(52,5 \%)$ dari jumlah total 40 responden diikuti dengan 9 responden $(22,5 \%)$ dengan lama diagnosis 13-24 bulan. Sementara ada 6 responden (15\%) dengan lama diagnosis 0-6 bulan, dan yang paling sedikit ada 3 responden $(7,5 \%)$ dengan lama diagnosis $25-36$ bulan.
Untuk klasifikasi NYHA, pada tabel ditemukan responden dengan NYHA I sebanyak 19 responden dengan 47,5\% dari jumlah total 40 responden. Sementara NYHA II sebanyak 18 responden (45\%), dan responden dengan NYHA III hanya didapatkan sebanyak 3 responden $(7,5 \%)$.

\section{Tabel 4 Distribusi Frekuensi Responden Berdasarkan Nilai Fraksi Ejeksi}

\begin{tabular}{lll}
\hline $\begin{array}{l}\text { Nilai Fraksi Ejeksi Ventrikel } \\
\text { Kiri }\end{array}$ & n & \% \\
\hline Preserved $(>50 \%)$ & 25 & $62,5 \%$ \\
Mid-rangeII $(40-49 \%)$ & 11 & $27,5 \%$ \\
Reduced $(<40 \%)$ & 4 & $10 \%$ \\
\hline Total & $\mathbf{4 0}$ & $\mathbf{1 0 0 , 0 \%}$ \\
\hline
\end{tabular}

Berdasarkan tabel diatas, bahwa responden gagal jantung yang memiliki nilai fraksi ejeksi preserved (normal) berjumlah 25 responden $(62,5 \%)$ melebihi $50 \%$ dari total jumlah responden. Pasien gagal jantung yang memiliki nilai fraksi ejeksi mid-range (sedang) berjumlah 11 responden dengan presentase sebesar 27,5\%, sementara hanya sedikit responden yang ditemui dengan nilai fraksi ejeksi reduced (menurun) yaitu berjumlah 4 responden dengan presentase $10 \%$.

Tabel 5 Distribusi Frekuensi Responden Berdasarkan Tingkat Gejala Ansietas

\begin{tabular}{lll}
\hline Tingkat Gejala Ansietas & n & \% \\
\hline Ringan & 17 & $42,5 \%$ \\
Sedang & 19 & $47,5 \%$ \\
Berat & 4 & $10 \%$ \\
\hline Total & $\mathbf{4 0}$ & $\mathbf{1 0 0 , 0 \%}$ \\
\hline
\end{tabular}

Berdasarkan tabel 5 didapatkan bahwa responden gagal jantung yang memiliki tingkat gejala ansietas yang sedang yaitu sebanyak 19 responden $(47,5 \%)$, diikuti dengan tingkat gejala ansietas ringan sebanyak 17 responden $(42,5 \%)$ dan yang paling sedikit adalah tingkat gejala ansietas ringan yaitu pada 4 responden $(10 \%)$. 
Vol 1 No 1 Desember 2019

Tabel 6 Hubungan Nilai Fraksi Ejeksi Ventrikel Kiri dengan Tingkat Gejala Ansietas

\begin{tabular}{|c|c|c|c|c|c|c|c|c|}
\hline & & lai Fral & $\mathrm{Ej}$ & ksi Ven & & Kiri & \multirow{3}{*}{ P Value } \\
\hline & & \multicolumn{2}{|c|}{$\begin{array}{c}\text { Preserved } \\
(>50 \%)\end{array}$} & \multicolumn{2}{|c|}{$\begin{array}{l}\text { Midrange } \\
(40-49 \%)\end{array}$} & \multicolumn{2}{|c|}{$\begin{array}{c}\text { Reduced } \\
(<40 \%)\end{array}$} & \\
\hline & & n & $\%$ & n & $\%$ & n & $\%$ & \\
\hline Tingkat & Ringan & 14 & $56 \%$ & 3 & $27,3 \%$ & 0 & $0 \%$ & \multirow{3}{*}{$\mathrm{p}=0,011$} \\
\hline Gejala & Sedang & 10 & $40 \%$ & 8 & $72,7 \%$ & 1 & $25 \%$ & \\
\hline Ansietas & Berat & 1 & $4 \%$ & 0 & $0 \%$ & 3 & $75 \%$ & \\
\hline \multicolumn{2}{|c|}{ Total } & 25 & $100 \%$ & 11 & $100 \%$ & 4 & $100 \%$ & \\
\hline
\end{tabular}

Peneliti menggunakan uji Kruskal-Wallis pada penelitian ini dan didapatkan nilai $\mathrm{P}$ value yang ditunjukkan oleh nilai $\mathrm{p}=0,011$ yang berarti terdapat hubungan antara nilai fraksi ejeksi ventrikel kiri dengan tingkat gejala ansietas pada pasien gagal jantung.

\section{PEMBAHASAN}

Masih sangat sedikit penelitian mengenai nilai fraksi ejeksi ventrikel kiri yang dihubungkan dengan kecemasan, terutama di Indonesia sendiri. Hal tersebut membuat peneliti kesulitan dalam mencari penelitian yang memiliki hasil yang mirip dengan penelitian ini.

Pada penelitian Deb Debasree, Khandelwal Smita, Kansal Nitin, dan Gonsalves James mengenai Depresi dan Ansietas pada Pasien Gagal Jantung di India Selatan mengatakan bahwa hanya sedikit penelitian yang menganalisis ansietas dalam konteks gagal jantung, namun dari sedikit penelitian yang didapat diketahui bahwa ada korelasi positif yang kuat antara ansietas dengan pasien gagal jantung terutama dengan prognosis yang buruk. ${ }^{11,12,13}$ Pada pasien gagal jantung dengan penyakit mental berupa ansietas memiliki hubungan dengan pengobatan dan hasil fungsional yang buruk. ${ }^{14}$

Dari kuesioner Beck Anxiety Inventory (BAI) menunjukkan bahwa pasien gagal jantung di RSU Mitra Medika Amplas dan RSU Putri Hijau Tk.II Kesdam I/BB Medan dengan tingkat ansietas yang paling banyak adalah tingkat gejala ansietas yang sedang yaitu sebanyak 19 responden (47,5\%), diikuti dengan tingkat gejala ansietas ringan sebanyak 17 responden $(42,5 \%)$ dan yang paling sedikit adalah tingkat gejala ansietas ringan yaitu pada 4 responden $(10 \%)$.

Berdasarkan hasil dari nilai fraksi ejeksi ventrikel kiri, bahwa pasien gagal jantung yang memiliki nilai fraksi ejeksi preserved (normal) berjumlah 25 responden $(62,5 \%)$ melebihi 50\% dari total jumlah sampel. Pasien gagal jantung yang memiliki nilai fraksi ejeksi mid-range (sedang) berjumlah 11 responden dengan presentase sebesar 27,5\%, sementara hanya sedikit pasien yang ditemui dengan nilai fraksi ejeksi reduced (menurun) yaitu berjumlah 4 responden dengan presentase sebesar $10 \%$.

Setelah menganalisis data menggunakan uji Kruskal-Wallis dengan nilai $\mathrm{P}$ yaitu 0,011 dapat diketahui bahwa terdapat hubungan yang bermakna antara nilai fraksi ejeksi ventrikel kiri dengan tingkat gejala ansietas pada pasien gagal jantung.

Pada penelitian ini didapati bahwa jumlah pasien gagal jantung wanita yang mengalami gejala ansietas lebih banyak dibandingkan dengan pasien gagal jantung pria, dan semakin bertambah umur pasien maka pasien akan semakin mudah merasa cemas. Hal ini sejalan dengan penelitian Katherine Easton, Karina Lovell dan Christi Deaton yang mengungkapkan bahwa wanita lebih mudah merasa cemas daripada pria, dan semakin bertambah usia maka tingkat ansietas juga akan meningkat. ${ }^{14}$

Dengan melihat hasil penelitian ini, dapat diketahui bahwa pasien dengan nilai fraksi ejeksi yang normal dapat mengalami tingkat gejala ansietas yang sedang bahkan tinggi. Hal ini dapat disebabkan oleh adanya faktor-faktor lain yang berhubungan dengan tingkat gejala ansietas, selain mengetahui adanya hubungan antara nilai fraksi ejeksi ventrikel kiri dengan 
tingkat gejala ansietas pada pasien gagal jantung, sehingga perlunya penelitian lebih lanjut mengenai faktor-faktor lain yang berhubungan dengan tingkat gejala ansietas tersebut pada pasien gagal jantung.

\section{KESIMPULAN}

Berdasarkan hasil penelitian dan pembahasan yang telah dijelaskan, maka dapat disimpulkan sebagai berikut:

1. Dari total 40 pasien gagal jantung dari dua Rumah Sakit di kota Medan yaitu RSU Mitra Medika Amplas dan RSU Putri Hijau Tk.II Kesdam I/BB Medan, didapatkan pasien gagal jantung dengan tingkat ansietas yang paling banyak adalah tingkat gejala ansietas yang sedang yaitu sebanyak 19 pasien $(47,5 \%)$, diikuti dengan tingkat gejala ansietas ringan sebanyak 17 pasien $(42,5 \%)$ dan yang paling sedikit adalah tingkat gejala ansietas ringan yaitu pada 4 pasien (10\%).

2. Dari total 40 pasien gagal jantung dari RSU Mitra Medika Amplas dan RSU Putri Hijau Tk.II Kesdam I/BB Medan, ditemukan bahwa pasien gagal jantung yang memiliki nilai fraksi ejeksi Preserved (normal) berjumlah 25 pasien $(62,5 \%)$ yaitu melebihi $50 \%$ dari total jumlah sampel. Pasien gagal jantung yang memiliki nilai fraksi ejeksi Mid-range (sedang) berjumlah 11 pasien $(27,5 \%)$, sementara pasien dengan nilai fraksi ejeksi Reduced (menurun) yaitu berjumlah 4 pasien (10\%).

3. Pada uji Kruskal-Wallis, didapatkan nilai $\mathrm{P}$ value yang ditunjukkan oleh nilai $\mathrm{p}=0,011$ yang berarti hubungan antara nilai fraksi ejeksi ventrikel kiri dengan tingkat gejala ansietas.

\section{REFERENSI}

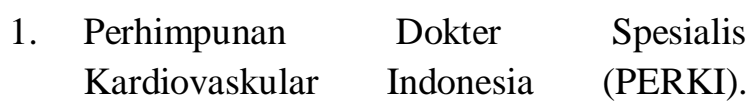

Pedoman Tatalaksana Gagal Jantung Edisi Pertama. Jakarta: PERKI; 2015

2. Longo DL, Kasper DL, Jameson JL, Fauci AS, Loscalzo J, Hauser S. Harrison's Principles of Internal Medicine. $18^{\text {th }}$ ed. New York: McGraw-Hill; 2011

3. World Health Organization. Prevention of Cardiovascular Disease. WHO Epidemiologi Sub Region AFRD dan AFRE. Genewa; 2016

4. Katon W, Lin EHB, Kroenke K. The association of depression and anxiety with medical symptom burden in patients with chronic medical ilness. Gen Hosp Psychiatry; 2007

5. Ehmouda F., Elbrasai H., Elneihoum A.M., Uric Acid in Chronic Heart Failure; Correlation with Prognostic Markers. Ibnosina Journal of Medicine and Biomedical Sciences. 2014; 6(5);208-212

6. Hobbs F. D. R., Roalfe A. K., Davis R. C., Davies M. K., Hare R., Prognosis of AllCause Heart Failure and Borderline Left Ventricular Systolic Dysfunction: 5 Year Mortality Follow-Up of the Echocardiographic Heart of England Screening Study (ECHOES). European Heart Journal 2007; 28;1128-1134

7. Koike A, Unutzer J, Wells KB. Impoving the care for depression in patients with comorbid medical ilness. Am J Psychiatry; 2002

8. Deswal, A. Recognition and Treatment Of Depression and Anxiety Symptoms in Heart Failure. Prim Care Companion J Clin Psychiatry; 2009

9. Global Health Estimates. Depression and Other Common Mental Disorders. WHO/MSD/MER/2017.2. World Health Organization; 2017

10. Varcarolis, E. M., \& Halter, M. J. Foundations of psychiatric mental health nursing: A clinical approach 6th ed. Missouri: Saunders Elsevier; 2010 
Vol 1 No 1 Desember 2019

11. Rothenbacher D, Hahmann H, Wüst B, Koenig W, Brenner H. Symptoms of anxiety and depression in patients with stable coronary heart disease: prognostic value and consideration of pathogenetic links Eur J Cardiovasc Prev Rehabil 2007;14:547-554

12. Grace SL, Abbey SE, Irvine J, Shnek ZM, Stewart DE. Prospective examination of anxiety persistence and its relationship to cardiac symptoms and recurrent cardiac events Pyschother Psychosom 2004; 73:344-352.

13. Celano, C. M., Villegas, A. C., Albanese, A. M., Gaggin, H. K., \& Huffman, J. C. (2018). Depression and Anxiety in Heart Failure. Harvard Review of Psychiatry. 2018; 26(4): 175-184

14. Easton, K., Coventry, P., Lovell, K., Carter, L.-A., \& Deaton, C. (Prevalence and Measurement of Anxiety in Samples of Patients With Heart Failure. The Journal of Cardiovascular Nursing. 2016; 31(4): 367-379. 